\title{
FERREIRA DE CASTRO, INTÉRPRETE DA AMAZÔNIA: REFLEXÕES SOBRE AS POÉTICAS DO ESPLENDOR E DA DECADÊNCIA EM A SELVA
}

\author{
FERREIRA DE CASTRO, INTERPRÈTE DE L'AMAZONIE: \\ RÉFLEXIONS SUR LES POÉTIQUES DE LA SPLENDEUR ET DE LA DÉCADENCE \\ DANS LE ROMAN A SELVA
}

Fernando Simplício dos Santos ${ }^{1}$

\begin{abstract}
RESUMO: O presente trabalho consiste em analisar o embate entre representação, imaginário e modernidade, identificado no romance A selva (1930), do escritor português Ferreira de Castro (1898-1974). Por esses meandros, propõe-se, igualmente, tecer uma apreciação a fim de verificar a maneira pela qual a produção literária em tela reconstrói, de forma crítica e inventiva, uma poética vinculada ao imaginário e outra correlacionada à decadência do universo amazônico, também detectadas, à sua maneira, em diferentes produções literárias publicadas na literatura brasileira, inclusive em obras ficcionais compostas na região norte do país.
\end{abstract}

PALAVRAS-CHAVE: A selva; representação amazônica; decadência e modernidade.

RÉSUMÉ: Ce travail a pour objectif d'analyser la façon dont le conflit entre représentation, imaginaire et modernité est organisé dans le roman intitulé A selva (1930), de l'écrivain portugiais Ferreira de Castro (1898-1974). En plus, dans l'univers de ce roman, on propose d'examiner le rapport entre la poétique de l'imaginaire et la poétique de la décadence. Dans le récit, cette caractéristique est soulignée par l'analyse des contradictions de l'espace de l'Amazonie brésilienne. Ainsi, tandis que la diffusion du progrès représente une expérience humaine positive, la modernité, contradictoirement, manipule l'individu et détruit son monde, par exemple.

MOTS-CLÉS: A selva; Ferreira de Castro; représentation de l'Amazonie; décadence et modernité.

A partir da análise dos projetos estético e ideológico de autores que se debruçam sobre a temática amazônica, como Ferreira de Castro, Abguar Bastos, Márcio Souza, Miltom Hatoum, Luiz Galdino, Rogel Samuel, Nunes Pereira, entre muitos outros, é possível mapear a maneira pela qual o gênero romance se estrutura e se transforma, historicamente, na região norte do Brasil, constituindo-se em uma poética particular. Nesse sentido, conceitos aplicados a estudos diversos (que resvalam em termos como, por exemplo, brasilidade, memória, amazoniedade, regionalismo, transculturação, transnacional e fronteira) permitem aprofundar nossas investigações, não só a respeito do modelo de determinado estilo "romanesco tropical", porém, ao mesmo tempo, contribuem para mapear certas poéticas do imaginário e da decadência,

\footnotetext{
${ }^{1}$ Universidade Federal de Rondônia - UNIR, Departamento de Línguas Vernáculas, Programa de Mestrado em Letras, Porto Velho, Rondônia, Brasil; https://orcid.org/0000-0002-7853-5713 ;

fernandosimpliciosantos@unir.br

Rev. Bras. Lit. Comp. Niterói, v. 22, n. 39, pp. 112-120, jan. /abr. 2020

https://doi.org/10.1590/2596-304X20202239fss 
correlacionadas a um ideal de esplendor e de pobreza; expressas, em território nacional, nos entrechoques de representações culturais variadas, desde o período pré-colonial até os séculos XX e XXI.

Há muito tempo, as culturas de povos amazônicos transmitem mitos, lendas e ritos, ampliando-se e transmutando-se, cada vez mais, em imagens e em formas discursivas prosaicas ou líricas - as quais, estando sobrepostas a sociedades múltiplas (isto é, com línguas e com culturas plurais), apresentam ricas visões de mundo; reivindicam e questionam o seu local de discurso; criam e recriam novas formas e conteúdos artísticos. No geral, é nesse sentido que, adaptando as teorias de Fernando Ortiz (1983) aos nossos propósitos, podemos falar de transculturação no universo amazônico, ou seja, transculturação compreendida como processo pelo qual se modificam, por exemplo, culturas e tendências artísticas indígenas em contato com outros povos ${ }^{2}$.

Em face disso, o caso de Ferreira de Castro torna-se peculiar, uma vez que, a fim de compor seu romance $A$ selva, sem dúvida, o escritor português trouxe para o Brasil experiências pautadas no universo europeu, mas diluídas em contato com o triste horizonte amazônico. A nossa hipótese é que, a partir de tais conhecimentos, o autor talvez tenha proposto uma interpretação literária das contradições da Amazônia, sem deixar de vinculá-las a uma poética do imaginário e da decadência, já delineada por volta dos séculos XV e XVI. Para a consecução de nossos objetivos, trabalhamos o conceito de arte sugerido por Antonio Candido, segundo o qual elucida que a literatura "é uma transposição do real para o ilusório, por meio de uma estilização formal, que propõe um tipo arbitrário de ordem para as coisas, os seres e os sentimentos..., implicando uma atitude de gratuidade" (2006, p. 63). Assim compreendido, o texto de ficção não só dialoga com aspectos da realidade, mas, também, os reposiciona de forma ampla e expressiva, destacando elementos estruturais ou internos que redimensionam certas funções da prosa e da poesia artísticas. Vejamos, nesse trabalho, como essas ideias estão dispostas na obra em questão.

O romance A selva foi publicado em 1930, muito tempo depois de Ferreira de Castro ter vivido no Brasil, isto é, esteve aqui entre os anos de 1914 a 1918. Em seus relatos, há informação de que, com apenas dezesseis anos, o romancista conheceu os seringais envoltos, em suas palavras, na "majestade verde, soberba e enigmática". Mas essa estadia na floresta brasileira o traumatizaria, marcando, assim, para sempre a sua vida, inclusive por causa do reconhecimento da exploração e da desigualdade que assolavam o país daquela época. Para compor A selva, observa-se que experiência de vida e elaboração artística, dadas a partir de um exercício da memória, fazem parte do projeto romanesco do autor e contribuem, da mesma forma, para identificar uma das maneiras representacionais desta narrativa, organizada na Europa, mas experenciada antes em terras amazônicas ${ }^{3}$.

Nesse compasso, o embate entre memória, passado e esquecimento representa o conflito de Ferreira de Castro em esquematizar, em forma de romance, a história do refugiado político e antigo adepto do monarquismo lusitano, Alberto - um jovem ex-estudante de Direito que (fugindo de Portugal para o Brasil em virtude da perseguição partidária, e depois de morar por

\footnotetext{
${ }^{2}$ Para o esclarecimento do conceito de transculturação, conferir: ORTIZ, Fernando. El contrapunteo cubano del azúcar y del tabaco. Cuba: Editorial de ciencias sociales, La Habana, 1983. Vide, especificamente, o capítulo "Del fenómeno de la 'transculturación' y de su importancia en Cuba".

${ }^{3}$ Em seu livro Formas da teoria (2002), José Luís Jobim verifica que, de tempos em tempos, a literatura tem como função defender e divulgar certa acepção de identidade nacional. Foi papel fundamental de literatos, historiadores e críticos da arte literária, além da análise da realidade nacional, compor escritos que pontuassem características que diferenciassem conteúdos nacionais da produção cultural, linguística e literária de Portugal, por exemplo. Assim, observa-se que, por vezes, a literatura se sobrepõe como premissa fundamental de brasilidade, com intuito de expressar o sentimento nacional como um todo. De qualquer modo, no caso de $A$ selva, há um impasse entre questões nacionais e estrangeiras.
}

Rev. Bras. Lit. Comp. Niterói, v. 22, n. 39, pp. 112-120, jan. /abr. 2020

https://doi.org/10.1590/2596-304X20202239fss 
um período de tempo com o seu tio, Macedo, em Belém do Pará) viu-se obrigado por este familiar a embarcar no vapor Justo Chermont até chegar ao Seringal Paraíso. Nesse local, antes de garantir pela lei de anistia a volta ao seu país, Alberto passa a enfrentar diversas humilhações, sobrevivendo em um sistema considerado, por muitos, como semi-escravocrata. Não é sem razão que as personagens Firmino, Agostinho, Tiago, Lourenço, entre outros companheiros de miséria e de desilusão, são explorados pelo seringalista Juca Tristão, cuja principal função é manter um projeto capitalista, sobretudo, a partir da extração do látex das seringueiras, no cerne da maior floresta do mundo.

$\mathrm{Na}$ esteira reflexiva de tais constatações, ao analisar o projeto romanesco de Ferreira de Castro, esboçado no prefácio d'A selva (2006, pp. 13-21) ${ }^{4}$, é possível destacar o entrechoque entre o imaginário (que versa sobre riquezas amazônicas) e o universo em desencanto (demarcado, entre outras peculiaridades, pelas experiências negativas vivenciadas também pelo próprio autor). De certa maneira, essas características vinculam-se a um tipo de "espelho deformante", muito comum às representações feitas sobre o "inferno verde", em particular, circunscritas pelos europeus, cujo papel muitas vezes foi o de desconfigurar lendas, mitos e ritos, criados e propagados na e pela grande Hileia brasileira.

\section{1}

De acordo com a tradição, sabe-se que a poética do imaginário se entrechoca com um dos conceitos de fronteira, que, embora para muitos seja claro e objetivo, atualmente tem que ser bem delimitado, em virtude de questões que vão muito além de categorias palpáveis ou factuais. Sobre essa questão, Sandra Jatahy Pesavento adverte que

as fronteiras, antes de serem marcos físicos ou naturais, são sobretudo simbólicas. São marcos, sim, mas sobretudo de referência mental que guiam a percepção da realidade. Neste sentido, são produtos dessa capacidade mágica de representar o mundo por um mundo paralelo de sinais por meio do qual os homens percebem e qualificam a si próprios, ao corpo social, ao espaço e ao próprio tempo. Referimo-nos ao imaginário, este sistema de representações coletivas que atribui significado ao real e que pauta os valores e a conduta. Dessa forma, as fronteiras são, sobretudo, culturais, ou seja, são construções de sentido, fazendo parte do jogo social das representações que estabelece classificações, hierarquias, limites, guiando o olhar e a apreciação sobre o mundo (Pesavento, 2002, p. 35-6)

A partir de tais definições de fronteira e de imaginário, pontua-se que, em vários excertos d'A selva, é possível verificar de que forma o narrador transpõe as barreiras territoriais, do regionalismo, do local, destacando aspectos do simbólico, do imaginário, configurados entre a Amazônia, Europa, especificamente, e Portugal. Por tal prisma, destaca-se um trecho significativo do romance de Ferreira de Castro, no qual o narrador compara a Hileia com parte da Europa:

Evocado dali, Portugal era uma quimera, não existia talvez. Pequeno e lá longe, os que o levavam na memória não estavam certos se viviam em realidade ou se sonhavam com as

\footnotetext{
${ }^{4}$ No depoimento expresso no prefácio d'A selva, Ferreira de Castro diz que “[...] durante dois anos, longos e negros como quando o tempo não era medido, deixei, efetivamente, de escrever romances, senão por mim, por ela própria, pela nova dor que tombara no meu espírito, muito mais forte, muito mais violenta do que a outra e do que todas as outras que eu já sofrera e havia de sofrer futuramente" (2006, p. 17-18). Nessa explicação, além do conflito entre memória, passado e esquecimento, constata-se o desencanto do autor e a necessidade de ter se "livrado", no sentido clássico de catarse, da elaboração d'A selva. Podemos dizer que, metaforicamente, se trata da libertação pela escrita como ato de purificação do espírito, diante dos tormentos vivenciados na Amazônia.
} 
narrações dos que tinham voltado das descobertas. Vendo os contrastes que se agigantavam de dia para dia, a própria personalidade deles entrava em dúvida e todo o passado se esfumava momentaneamente, tudo lhes parecia ilusório. Eles seriam, porventura, uma alucinação sobrevivente de alguém que morrera pensando em fábulas bíblicas, em mundos pré-históricos, e, quando menos o esperassem, desvanecer-se-iam totalmente, como espectros de pesadelo. Só o perigo, mais temido do que em outra parte, por usar máscaras desconhecidas, os reconduzia à realidade, humanizando-os ante eles próprios. (Castro, 2006, p. 65)

Aqui, é nítido o embate entre memória e passado; presente e esquecimento, em que o fabuloso e o mítico se sobressaem quando comparados às "categorias do real". Nessa passagem, as fronteiras culturais ou territoriais são, praticamente, abolidas por uma mente que trabalha o ilusório, a alucinação, o aparente, sobrepostos a uma perspectiva particular. Comparada com a Europa, Amazônia é magistral, enigmática e soberana. Nela, encontramos mistérios impenetráveis, mas que concomitantemente desiludem. Dito isso, agora é possível ampliar mais as nossas questões teóricas e analíticas.

De certo modo, aproximando-se das reflexões referidas acima de Sandra Jatahy Pesavento, pode-se mencionar o livro Cultura amazônica: uma poética do imaginário (2019), de João de Jesus Paes Loureiro, uma vez que, assim como Pesavento, ele não deixa de reconhecer, em seu texto, a existência de uma rica produção estética que perpassa pela compreensão da ressignificação daquilo que se entende, no geral, por "representações dos imaginários". Só que, no caso de Paes Loureiro, há a ênfase às configurações ficcionais de povos ameríndios - muitos estando em regiões de fronteiras, isto é, junto às linhas simbólicas ${ }^{5}$ e fantasiosas, as quais representam, para este teórico, um rico

universo mitológico produzido pela realidade imaginária, [pois] o universo dos encantados dos rios e das matas tem sido um dos ângulos mais fecundos para relacionar, compreender e explicar, na Amazônia, a relação dos homens entre si e com a natureza. Região de silêncios, recortada pela emaranhada variedade dos rios na paisagem verde da floresta, a Amazônia torna-se um fertilíssimo campo de germinação para as produções do imaginário do homem, na fruição, no compartilhamento, na intervenção ou na explicação simbólica de sua realidade (Paes Loureiro, 2019, p. 110)

Paes Loureiro defende a proposição de que seja "possível identificar na cultura amazônica um imaginário poetizante estetizador, governando o sistema de funções culturais, tendo como suporte material a natureza e desenvolvendo-se por meio da vaga atitude contemplativa própria do homem da região em sua imersão no devaneio" (Paes Loureiro, 2019, p. 95). Então, conforme Paes Loureiro, por meio da analogia entre imagens e formas discursivas atinentes ao universo representacional da Amazônia, uma das funções do artista seria decodificar todo um sistema configurado pelo imaginarium em torno da grande floresta, destacando-se: a natureza, os rios, os ritos, danças, bem como todas outras produções que enriquecem a fantasia.

Por sua vez, no ensaio intitulado A invenção da Amazônia (1994), Neide Gondim observa o modo pelo qual diversos europeus cunharam e, a um só tempo, deturparam símbolos e rituais

\footnotetext{
${ }^{5}$ Em seu clássico estudo sobre Makunaima/Macunaíma: contribuições para o estudo de um herói transcultural (2015), Fábio Almeida de Carvalho acrescenta que, em regiões de fronteiras, “o lendário passa por 'um processo de reestruturação no bojo do qual assume função diferenciada e valor diverso, em razão da influência de filtros que atuam na mediação dos circuitos de interação, de trocas e de apropriação de elementos oriundos de distintas esferas da cultura"' (Carvalho, 2015, p. 73). Com efeito, esse é o caso da literatura publicada em certas partes da região amazônica, o que, igualmente, faz com que uma boa parcela da crítica contemporânea seja obrigada a rever determinadas acepções, em especial, presentes nas histórias da literatura brasileira, por exemplo.
} 
de povos e de culturas amazônicas, elaborando, em decorrência disso, uma espécie de "imaginário desfigurante", notadamente esquematizado com advento da exploração econômica de terras. Tudo isso justaposto às questões que rondam há muito tempo o pensamento coletivo e que atingem crenças de povos que habitam determinadas regiões. Assim, Gondim sublinha que, em virtude de questões que giram em torno da região amazônica,

pressionados por adversidades comuns à época, os homens sonham encontrar o Paraíso e a fonte da eterna juventude. A tradição religiosa dizia que um grande rio nascia naquele local aprazível, cujas águas encobriam riquezas, e não muito longe, uma fonte convidava para a total supressão dos males sociais, onde a fome, as doenças e as pestes continuamente dizimavam respeitáveis contingentes humanos. Esse local foi encontrado pelos expedicionários de Orellana e se localizava na região amazônica. Sucessivamente visitada, principalmente depois de liberada a navegabilidade do Rio das Amazonas pelo governo português, para aquela região composta de enormes rios e florestas compactas, dirigem-se atenções e erigem-se verdades; confrontam-se teorias e refutam-se ou confirma-se hipóteses. (Gondim, 2019, pp. 13-14)

De uma parte, Gondim destaca que, se as viagens ao Novo Mundo, realizadas entre os séculos XV e XVII, nutriam um imaginário configurado na utopia do Paraíso, da descoberta da fonte da juventude e de muitas riquezas; de outra parte, os idealizadores dessas mesmas empreitadas insistiram em apagar uma parcela significativa de ideais comuns ou de traços culturais (inclusive as línguas, mitos e ritos religiosos) de inúmeras comunidades ameríndias. Por tal focalização, para compreender, histórica e esteticamente, romances elaborados na região amazônica, como no caso d'A selva, de Ferreira de Castro, é preciso entender, sobretudo, que esta narrativa problematiza a representação de questões que circunscrevem o confronto entre a tradição milenar da região amazônica e sua histórica destruição. Não sem razão, é imprescindível frisar que tal aspecto trata do secular confronto entre civilização e barbárie; o progresso e a pobreza; ou, em uma só analogia, entre a modernidade e a tradição. E, não por acaso, no romance, para a floresta majestosa e enigmática, iam todos aqueles que desejavam obter riquezas, explorar o ouro e extrair o látex da seringueira. Sendo assim,

era, então, a Amazônia um imã na terra brasileira e para ela convergiam copiosas ambições dos quatro pontos cardeais, porque a riqueza se apresentava de fácil posse, desde que a audácia se antepusesse aos escrúpulos. Com os rebanhos, idos do sertão do Noroeste, demandavam a selva exuberante todos os aventureiros que buscam pepitas de oiro ao longo dos caminhos do Mundo. E como não era na brenha espessa que se encontrava, para os ligeiros de consciência, a aurífera jazida, quedavam-se os ladinos em Belém e Manaus, a traficar com o esforço mitológico dos que, entre todos os perigos, se entregavam à extração da borracha (Castro, 2006, p. 28)

Neste trecho, o narrador nos fala do caráter mítico da floresta. Não obstante, em meio às promessas de riquezas submersas no "paraíso infernal", está a sepultura daqueles que nele ousaram se aventurar, ainda que, às vezes, a exuberância faça parte das descrições delineadas pelo relator dos fatos - conforme elucida o trecho abaixo:

[...] O luar descia, peneirando-se por entre a folhagem adormecida, pincela aqui, pincela acolá, cobrindo de joias extravagantes os troncos e os seus rebentos. De quando em quando, um rasgão, um jacto doirado que ligava o igapó ao céu, marcava nitidamente a verdadeira altura da selva. Em redor do espelho iluminado, as sombras mostravam-se 
diáfanas e a água, sob os galhos ribeirinhos, sugeria profundidade abissal. E sempre, sempre, a miragem deslumbrante da floresta copulada pela luz de quimera. Para a frente, dir-se-ia não haver caminho; a vista detinha-se nos fustes mais grossos, onde o luar se ia esbatendo, como se tudo ali findasse. Mas quando a proa avançava para o obstáculo, a selva rasgava-se de novo, a ilusão repetia-se, o mundo fabuloso continuava. (Castro, 2006, p. 110)

Nessa sintonia estabelecida entre imagens e formas discursivas, entre esplendor e decadência, demarcando descrições da paisagem de luzes e obscuras d'A selva, nota-se que as duas últimas passagens citadas do romance estão em consonância com a comparação teórica feita entre João de Jesus Paes Loureiro e Neide Gondim, uma vez que todas essas abstrações analíticas e teóricas partem do pressuposto de um confronto: entre o imaginarium (tracejando certa acepção estética de beleza) e a decadência (destacando contradições relativas a uma ideia ímpar de civilização). Ainda que ambos os teóricos citados reconheçam esse embate, é fundamental analisar o modo como, na região restringida pela grande floresta tropical, a arte e a literatura configuram e desconfiguram esses dois polos ambivalentes. Nesse sentido, adaptando aos nossos objetivos algumas reflexões de Paul Ricœur, é possível frisar estratégias hermenêuticas que reconheçam os confrontos entre as ideias de "imaginário", de "fronteira" e de "representação".

No decorrer de sua carreira intelectual, Paul Ricœur ${ }^{6}$ pontua duas categorias básicas de interpretação: a primeira se constitui a partir da reconciliação dos sentidos; a segunda se estabelece por meio de um exercício "da suspeita", isto é, do exame das contradições. Uma almeja esgotar o sentido, pretendendo a qualquer custo o restaurar desde sua "origem", esboçando de tal forma uma crença excessiva na linguagem que visa restringir os significados à determinada noção de verdade. Em contrapartida, a outra é elaborada para sondar de modo ininterrupto as ilusões, as fantasias ou as mentiras que são figuradas ou desfiguradas pela própria consciência, ou seja, pelos fantasmas que rondam o imaginário. É por esse motivo que, vistas por este prisma, as pretensões da consciência ou do imaginarium se tornam falsas. A função essencial desta última categoria hermenêutica ou interpretativa é questionar os moldes de representação que têm como finalidade demonstrar os fundamentos em torno de uma singular veracidade. A partir de tal crítica, o objetivo do intérprete é reerguer os pilares que sustentam uma teoria analítica a partir da "era do esquecimento". É nesse sentido que, no contexto contemporâneo, precisamos de uma teoria do romance que considere os embates propiciados pelos confrontos das significações; que destaque os entrechoques representacionais.

Portanto, por meio de tais sentenças, podemos compreender com mais profundidade o sentido da decadência aqui trabalhado. Esta última não pode ser entendida apenas por meio do senso comum. Para nós, a decadência passar a estar vinculada à imagem de um "baú de memórias", que ainda que estejam, de uma parte, configuradas em torno dos significantes que englobam: a floresta, os rios, os ritos, os mitos, as danças, os bichos, as lendas e outros patamares em que habitam os seres fantásticos, de outra, são traduzidas em meio aos escombros do progresso: tal "como um ritual secularizado - através do culto dedicado à beleza, mesmo sobre as formas mais profanas" das ruínas da civilização (Benjamin, 1994, p.171). Assim nos fala "o souvenir benjaminiano", compreendido como alegorias de um raro legado passadista, "“como se este fosse um conjunto de bens mortos'; lembranças de uma experiência morta"

${ }^{6}$ Conferir: De l'interprétation (1965), “Le symbole donne à penser” (1959), De l'interprétation: essai sur Freud (1965, p. 17), "Hermenêutica dos símbolos I e II (1969)", O conflito das interpretações (1988), entre muitos outros.

Rev. Bras. Lit. Comp. Niterói, v. 22, n. 39, pp. 112-120, jan. /abr. 2020 
(Bolle, 1994, p. 132). Sua missão é oferecer um tom inovador de decadência a múltiplas tendências da tradição e de nosso próprio tempo.

No romance em pauta, a selva enervava e angustiava seus habitantes os seringueiros, mesmo que "alguém acreditasse ainda naquilo de que eles já descriam; e os remoques só terminavam depois de o "brabo" se ter familiarizado com os segredos da vida local e resignado ao extermínio das suas próprias ilusões" (Castro, 2006, p. 69). Nesse universo repleto decepção e de melancolia, no qual os ideais de civilização se transformam em ícones contraditórios da derrota humana, o protagonista se defronta com elementos que, em outra fase de sua vida, fariam parte de seu próprio "baú de memórias".

A trajetória de Alberto traçada na floresta amazônica remonta a um triste legado passadista: da pobreza, da miséria, das imagens da solidão. Nota-se que, num momento crucial da narrativa, Alberto se surpreendia com

quatro ou cinco cruzes rústicas apodrecendo entre erva alta, nos pontos mais elevados da margem. A visão perdia-se rapidamente, abafada pela selva que avançava sobre o pequeno cemitério, a espalhar a vida sobre a terra da morte. Contudo, essas necrópoles humildes, onde não existiam mármores nem solenes epitáfios, constituíam o único elemento romântico daquelas solitárias paragens (Castro, 2006, p. 45)

Esse cemitério descrito é simbólico, porque exerce o poder de reconfigurar toda a acepção romântica e milenar, a qual, conforme a tradição, considerava a Amazônia como um "Paraíso Perdido"; um "Eldorado" dentre as agruras da civilização. Na derradeira passagem mencionada d'A selva, nota-se que as sepulturas humildes não têm nem as lápides nem qualquer outro tipo de identificação daqueles que nelas jazem. Nas palavras do narrador, a Amazônia se torna uma "terra da morte". Em decorrência das descrições dessas paragens das desilusões (isto é, desses locais que delineiam as verdades e as mentiras que versam sobre a lendária floresta), há também as alusões aos símbolos do progresso, da civilização - representados, n'A selva, pelas grandes conquistas ou suntuosas construções propagadas por Portugal, como, por exemplo, pelo forte do Príncipe da Beira. E, em seguida, entendemos a ressignificação desses mesmos símbolos transmutados em ruínas, em escombros da história. Sob tal perspectiva, Alberto interpreta com minúcia as

ruínas duma soberania longínqua, ferro podre, bronze com azinhavre, falava de 203 dias de viagem através da floresta, que tantos levaram os construtores da barricada, do Pará ao lugar onde o rei de Portugal queria ostentar canhões com a sua coroa. E essa artilharia, agora desfeita, devorada pela ferrugem, fora conduzida através das cachoeiras, numa primeira, titânica e muda batalha com os elementos que se opunham à vontade dominadora do lusíada. (Castro, 2006, p. 67)

Devido às concepções do narrador e de Alberto, A selva trata da representação de um espaço que, diante da expectativa criada pelo imaginário sobre a Hileia, passa a um só tempo por um processo de desencantamento. A ideia de decadência se sobressai em todo o decorrer do livro de Ferreira de Castro. Acrescente-se a isso que, no contexto em que esta obra foi composta, instaurava-se o fim da exploração do látex na região amazônica, demarcando seu período de declínio.

$\mathrm{Na}$ esteira reflexiva de tais constatações, observa-se que, ao confrontar as duas formas de representação identificadas em $A$ selva, destacam-se dois campos simbólicos: 1) o primeiro envolto nas imagens de um lugar místico, utópico, das amazonas, das riquezas e da exuberância; 2) o outro está justaposto à noção pautada pelo "inferno verde", pela escravidão, pela miséria, pela degradação do meio em que o ser humano vive sem espaço para os sonhos. Por

Rev. Bras. Lit. Comp. Niterói, v. 22, n. 39, pp. 112-120, jan. /abr. 2020 
conseguinte, é importante frisar que tudo isso trata de incoerências que vão de encontro a determinado pensamento coletivo propagado, através dos séculos, em torno da Amazônia e de suas tradições. Portanto, aqui, o embate das representações é nítido e demarca, por um lado, um campo permeado por crenças, esperanças, aspirações, e, por outro, um universo pleno de tristeza, falsidades, mentiras e desencantos.

Em todo caso, devido ao expressivo teor literário d'A selva, por vezes, destaca-se a correlação ambivalente entre imaginário e fronteira, já que aparecem sobrepostos a uma potência interpretativa capaz de alimentar uma rica cadeia de representações. Dessa feita, constata-se que a atmosfera contornada pelo romance de Ferreira de Castro tem como uma de suas funções traçar uma rica teia de significações. Em torno de um mosaico que capta imagens e formas discursivas que transmitem a ideia de uma "natureza morta", a um só tempo, a floresta: a) transmuta as atitudes, as crenças e os valores; $\boldsymbol{b}$ ) aniquila os desejos ou os sonhos mais recônditos; $\boldsymbol{c}$ ) modifica a perspectiva do narrador cujo papel, por vezes, é transpassar as fronteiras entre Brasil e Europa, por exemplo; $\boldsymbol{d}$ ) representa um ambiente em que a memória está em constante conflito, até que, paulatinamente, a selva delineie a destruição de si mesma e de todos aqueles que a ela pertencem. De maneira contraditória, na trama, tudo isso é expresso em nome do progresso ou da civilização, uma vez que esta última, nas palavras do próprio Ferreira de Castro, tem como uma de suas mais importantes funções aniquilar todas as ilusões devido ao seu "contacto diário com a miséria".

\section{REFERÊNCIAS}

BASTIDE, Roger. Brasil terra de contrastes. São Paulo: Difusão Europeia do Livro, 1980. BENJAMIN, Walter. Magia e Técnica, arte e política: ensaio sobre literatura e história da Cultura. São Paulo: Brasiliense (Obras Escolhidas) VI, 1994.

BERMAN, Marshall. "Introdução: modernidade hoje, ontem e amanhã". In: Tudo que é sólido desmancha no ar: a aventura da modernidade. Trad. Carlos Felipe Moisés \& Ana Maria. São Paulo: Companhia das Letras, 1986, pp. 24-49.

BOLLE, Willi. A Fisiognomia da Metrópole Moderna: representação da Metrópole em Walter Benjamin. São Paulo: Editora da Universidade de São Paulo, 1994.

BRAGA, D. R. F. and, SILVA, A. M. L. "A Selva, de Ferreira de Castro: representações das margens e das minorias". Revista literatura \& literatura, vol. 15, n. 24, 2013, p. 143-163, http://revistas.fw.uri.br/index.php/revistalinguaeliteratura/article/view/804/1562

CANDIDO, Antonio. Literatura e sociedade. Rio de Janeiro: Ouro sobre azul, 2006.

CARVALHO, Fábio Almeida de. Makunaima/Macunaíma: contribuições para o estudo de um herói transcultural. 1.ed. Rio de Janeiro: E-papers, 2015.

DE ARAÚJO, Wilson Alves. and, SOUZA BRITO, Jorge Nathan., PROFICE, Christiana

Cabicieri. “'A selva' de Ferreira de Castro: cenário, dimensão e sustentabilidade”. Ambiente \& Sociedade, [online], vol.21., Epub, nov., 29, 2018, p. 2-16, http://www.scielo.br/scielo.php?script=sci_arttext\&pid=S1414753X2018000100318\&lng=en\&nrm=iso\&tlng=pt 
FRAGA, José Carlos Vieira. Ferreira de Castro: duas narrativas e uma trajetória. Dissertação (mestrado). Pontifícia Universidade Católica do Rio de Janeiro. Departamento de Letras, 2010. GONDIM, Neide. A invenção da Amazônia. 3.ed. Manaus: Editora Valer, 2019.

JOBIM, José Luís. "A história da literatura e as trocas e transferências literárias e culturais", Veredas 10, 2008, p. 105-116, https://digitalis-

dsp.uc.pt/bitstream/10316.2/34472/1/Veredas10_artigo7.pdf

. Formas da teoria. Rio de Janeiro: Caetés, 2002.

. Literatura e cultura: do nacional ao transnacional. Rio de Janeiro: EdUERJ, 2013.

ORTIZ, Fernando. El contrapunteo cubano del azúcar y del tabaco. Cuba: Editorial de ciencias sociales, La Habana, 1983.

PAES LOUREIRO, João de Jesus de. Cultura Amazônica: uma poética do imaginário. 5. ed. Manaus: Editora Valer, 2019.

PESAVENTO, Sandra Jatahy. "Além das fronteiras". In: MARTINS, Maria Helena (Org.). Fronteiras culturais - Brasil, Uruguai, Argentina. Cotia, SP: Ateliê editorial, 2002, p. 35-39.

RICOEUR, Paul. Interpretação e ideologia. Trad. Bras. H. Japiassu. Rio de Janeiro: F. Alves, 1990.

RICOEUR, Paul. «Le symbole donne à penser», Esprit, Paris, n. 8, 1959, pp. 60-76, http://www.fondsricoeur.fr/photo/symbole\%281\%29.pdf . De l'interprétation: essai sur Freud. Paris : Éditions du Seuil, 1965.

- . «'identité narrative». Esprit. Paris, n. 7-8, 1988, p. 295-304, https://esprit.presse.fr/article/ric\%C5\%93ur-paul/l-identite-narrative-12865

. Le conflit des interprétations. Paris: Éditions du Seuil, 1969.

—. «Le paradoxe politique». Esprit. Paris, n. 6, 1957, p. 721-743, https://esprit.presse.fr/article/paul-ricoeur/le-paradoxe-politique-24123

RICOEUR, Paul. O conflito das interpretações. Trad. Port. M. F. Sá Correia. Porto: Réseditora, 1988.

PRADO Júnior, Caio. história econômica do Brasil. 43. ed. São Paulo: Brasiliense, 1998.

SZTUTMAN, Renato. "Sobre a ação xamânica". In: Gallois, Dominique (org.). Redes de relações nas Guianas. São Paulo: Associação Editora Humanitas/NHII, 2005.

Fernando Simplício dos Santos é docente da Universidade Federal de Rondônia, doutor em Teoria e História Literária pela UNICAMP, e autor de artigos em periódicos e capítulos de livros, cujas referências completas encontram-se em http://lattes.cnpq.br/3201471894283721

Submetido em 11/11/2019

Aceito em 21/12/2019

Rev. Bras. Lit. Comp. Niterói, v. 22, n. 39, pp. 112-120, jan. /abr. 2020 